\title{
Green Entrepreneurship: The Emerging Paradigm for Sustainable Growth and Development in India- A Study of the Millennials
}

\author{
Sanjeela Mathur ${ }^{*}$ and Neelam Tandon \\ Jagannath International Management School, New Delhi - 110005, India; \\ sanjeela.mathur@jagannath.org, neelamtandon2007@gmail.com
}

\begin{abstract}
Objectives: This paper tries to study and understand the potential opportunities and challenges faced by green entrepreneurs in India. It attempts to provide directions and a viable solutions to prevent further ecological degradation through green entrepreneurship. Methods/ Statistical Analysis: The research, being, exploratory in nature, utilizes both primary and secondary data for the purpose. Primary data has been collected from millennial, student respondents, who are either graduates or pursuing their final year of post-graduation in management. A sample size of 130 students have been taken through random sampling method. Factor loading was employed and Analysis of Variance (ANOVA) and a hypothesis test along with a correlation coefficient between factors also helped the study to draw conclusions with regard to factors that prove to be motivational and also the key barriers to green entrepreneurship in India. Findings: The study reveals that in general, millennials possess high level of environmental awareness. However, a weak Correlation can be inferred between gender, age and environmental knowledge, beliefs and attitudes. Environmental concerns were measured on various issues and a standard factor analysis through weighted method indicated that high concerns significantly impacted the demand and supply of green products and several factors ranging from emerging opportunities, creative interventions, availability of technological alternatives were key motivational factors. Emergence of various sectors in Indian economy was found by the study as an emerging green driver to leverage existing resources, knowledge of green technology, a growing entrepreneurial climate. However, a factor analysis of the barriers to green entrepreneurship were found to be -the absence or limited knowledge of green technology and high investment costs , absence of funds to undertake risk in the sector along with inability to understand potential benefit accrued from green businesses is believed to be a serious discerning factor amongst the respondents. Application/ Improvements: Research is useful to understand the motivational factors as the study provides useful insights into consumer attitudes, beliefs and values which can be helpful to marketers and entrepreneurs to design their strategies.
\end{abstract}

Keywords: Ecopreneurs, Environmental Entrepreneurship, Green Behaviour, Millennial Sustainability

\section{Introduction}

A recent study by World Bank has highlighted the increasing rate of environmental degradation of air and water pollution, deforestation and natural disasters leading to climate change globally. Climate change is an inevitable challenge faced by the globe in the twenty- first century and it has become a responsibility of both the developed economies as well as developing economies to evolve sustainable solutions to the crisis. Climate change has been defined by Intergovernmental Panel on Climate Change (IPCC) as "change in the state of the climate that can be identified (e.g. using statistical tests) by changes in the mean and/or the variability of its properties, and that persists for an extended period, typically decades or longer. It refers to any change in climate over time, whether due to natural variability or as a result of human activity. This usage differs from that in the United Nations Framework Convention on Climate Change (UNFCCC), where climate change refers to a " change of climate that

${ }^{*}$ Author for correspondence 
is attributed directly or indirectly to human activity that alters the composition of the global atmosphere, and that is in addition to natural climate variability observed over comparable time periods " One of the chief causes for this rapid change in climate can be attributed to global warming, depletion of natural resources and over use of fossil fuels and increased waste generation which have not helped to conserve nature but deteriorated the quality of air, water, land and damaged the fertility of soil and oceans at large. Failure to address the issues have affected sectors like agriculture, energy, tourism and many others. Thus, while developed economies have to, traditionally bear the brunt of it, it is also a fact that they have compounded the problem by contributing to the perils of climate change by adopting processes in manufacturing and production which have not helped conserve natural resources. It is in this context that green entrepreneurship and green processes emerge as a new paradigm to socioeconomic and ecological shifts.

Green entrepreneurship is a world- wide phenomenon which embodies a new set of knowledge and measures to not only provide solutions to increasing environmental issues, global warming and resource crunch but also sets new standards for capacity building and capacity enhancement. It opens venues for innovation, technology adaptation, employment generation and in the process solve problems of unemployment faced by many developing nations and host of connected issues at local and community level. Today, India has the largest youth population in the world. It is imperative that the nation and its youth recognize the potential of a green economy and the required focus and thrust is provided in the economy to encourage more and more green entrepreneurs to become a part of this global movement. Adaptation of green business practices can throw open a host of opportunities to these ecopreneurs. In order to make this a reality, policies, measures need to be undertaken to reduce carbon footprint across various sectors and industries and discourage traditional methods that are energy consuming and add to high pollution levels. Inclusive growth which caters to all levels along with a potent network of manufacturers, dealers and marketers can mark a shift for green entrepreneurship from a subject of elite to everyday practice by the enterprises which are catering to the bottom of the pyramid.

The earliest precedent of Green Entrepreneurship can be traced back to 1960 when the western world realized the increasing perils of industrialization and the imminent problems of environment that the globe would have to face. This led to the establishment of Environmental Protection Agency ( EPA ) with the sole objective of working towards deriving plausible solutions to environmental damage. This opened new business opportunities for not only green marketers but also created avenues for product modifications, new sources of raw material and also developing alternatives to traditional business processes. The concept of 'Green Entrepreneurship can be traced back toBerlef, who introduced terms like recycling, renewable energy, preservation etc. In his book 'Business opportunities that can save earth and make you money', he espouses the cause of environment and declares that "one man's garbage is another man's treasure". Thus, entrepreneurs came forward in all types of enterprisessmall, medium and micro industries fuelling economic growth along with contributing to environmental issues, thereby solving community problems with innovative ideas. Hence along with profit motive a new breed of individual entrepreneurs emerged 'potentially moving towards reorganized ecological society' Entrepreneurship came to be recognized with a new spirit of enthusiasm for environmentalism with new ideas Thus, it was only in the late 1990s that environmental entrepreneurship sought attention and terms like ' environmental entrepreneurs', 'green entrepreneurs', 'eco entrepreneurs ', and 'ecopreneurs' came to be widely used for individuals engaged in activities to not only earn profit but also seeking sustainable advantage . Ecopreneurship came to be defined as individuals who invested in green business processes to earn profit as well as serving society through protecting the environment. Hence, green entrepreneurship began to be associated with introducing innovative products and services which targeted the new emerging market opportunities].Thus, research into the literature regarding definition of environmental entrepreneurship ${ }^{6-9}$ refer to the beginning of an enterprise which is aligned towards protection of the environment and concern for environment became the core value and identity of such businesses which helped them to promote themselves as differentiated and thereby acquiring a 'competitive advantage'

At this stage, it becomes important to point out that with due growth in concern for environment, has also invited scholars to examine the nature of green entrepreneurship from various perspectives. One of these is that green entrepreneurship can be classified on two categories. One is which when established big 
business houses adopt green approach to their business management and the other are the start-ups who have environment concern at the centre of their process and are based on natural and ecological resources. The first criterion of companies adopting ecological processes is to gain competitive advantage and to enable product differentiation 1 . This theory argues that there is a strong relationship between environmental management as a part of the corporate responsibility of companies and thereby competitive advantage and innovation gains ${ }^{2,213}$. At the same time, some researchers believe that in adopting this approach, the established businesses do not incur any additional cost that can adversely affect the business 1 . It is argued in similar breath that natural resources would provide intangible benefits to these companies which cannot be easily imitated ${ }^{\text {I }}$. Hence, in this context, green entrepreneurship can be defined as an attempt by individuals to "popularize their environmental friendly practices through market or non- market routes". The second category of businesses, who have begun with the objective of environmental protection, Lober defines green entrepreneurship as 'the creation of new products, services or organisations to meet market opportunities' Cohen and Winn fif elaborated further and considered such businesses as 'sustainable' and with the objective of "bringing into existence future goods and services with economic, psychological and social consequences". Thus, early literature in green entrepreneurship was a conjunction of theories of economics and environmental economics. Moreover, research in the area highlights another approach towards green entrepreneurship and the basis of this is the level of development of an economy. Thus develop nations look at green entrepreneurship from the perspective of innovation and offering new products to new opportunities 19 . On the other hand, developing nations like India, entrepreneurs look at green entrepreneurship as developing affordable products to meet the needs of the poor and at the same time endeavouring to make them green, thus contributing to transformation of economy.

Nevertheless, a departure from earlier theories, studies have also been carried out to determine the motivational factors for individuals to undertake green entrepreneurshipe-23, At different stages of study, researchers have contributed to this spectre of entrepreneurship which have varying conclusions and hence inconclusive to a great extent. Yet another dimension of the study is directed towards understanding the role of private and public institutions and their role in encouraging or inhibiting green entrepreneurship ${ }^{26-25}$.At this juncture, an important contribution by Lennenen in green entrepreneurship needs to be mentioned as Lennenen argues that challenge to create a market for green products, unfamiliarity with the investment community and also lack of awareness for green products can prove to be some of the core barriers to green entrepreneurship.

However, it can bejustified that green entrepreneurship is nothing short of a movement and a viable solution to various issues, be it ethical, social or environmental in nature 阴.

This paper is an attempt to understand the factors that contribute to motivate millennial in India towards green entrepreneurship, the challenges faced in their start- ups and the process thereof. While there is extensive literature on entrepreneurial roles and nature that fills the society and also explaining the significance of entrepreneurial orientation ${ }^{3}$, and also the contribution of institutions and culture ${ }^{55,37}$ reflect the embeddedness of the economic environment in social and structural relationships", most of this literature is confined to the western developed nations and do not cover the predominant differences in emerging economies like India.

\section{Significance of Study}

In an emerging economy like India, it was not, until| pointed out the growth opportunity at the 'Bottom of the Pyramid', most entrepreneurs were skeptical about addressing the entrepreneurial innovations along with environmental concerns on that scale. Green innovation remained an elite word meant for large corporations and well established corporations and as a tool for corporate social responsibility and enhancing reputation. However, with changing consumer behavior and increasing developments in the education, income and other social index, green entrepreneurship is catching the attention of the newer generation and government and public institutions are playing a positive role in encouraging environmental concerns. The next decade is bound to witness rapid globalization, industrialization, technology deepening in the economy. Resources, being limited, the globe has to find means to reach in a manner which is not detrimental to natural resources and to survival of mankind on this planet. Thus this paper attempts to bridge the gap between green consumers and green entrepreneurs who can play a pivotal role in ushering 
the much required environmental protection and conservation to the forefront in the Indian context. Figure 1 shows the benefits of Green Business.
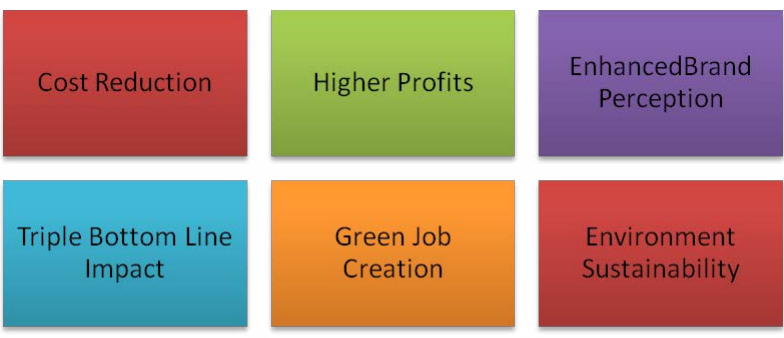

Better Reputation

amongst Social

and Governance

Stakeholders

Figure 1. Benefits of Green Business.

\section{Research Objectives}

The chief objective of this research is to understand and investigate into the following areas:

- Relevance of Green Entrepreneurship in encouraging business growth and economic prosperity.

- Critical examination of motivational factors for Green Entrepreneurship.

- To examine the challenges faced in Green Entrepreneurship.

- Role of education, government support and environment for conducive growth of entrepreneurship.

\section{Hypothesis}

Ho-Environmental consciousness and awareness amongst millennials builds positive attitude towards green entrepreneurship.

H1-Motivation for green entrepreneurship depend upon increasing awareness for environment- friendly and green products amongst consumers.

H2-Relevance of green entrepreneurship is impacted by shifts in potential demand and government policies in various sectors in India.

\section{Research Methodology}

The research, being, exploratory in nature, utilizes both primary and secondary data for the purpose. Primary data has been collected from student respondents who are either graduates or pursuing their final year of postgraduation in management. A sample size of 130 students have been taken through random sampling method. The purpose of the survey was to gather information regarding awareness and concern for environment amongst these students and also to understand the factors that motivate these respondents to choose entrepreneurship over placement in corporations. Data collection was qualitative in nature and both analytic induction method and logical analysis methods were used to interpret data and draw conclusions.

\section{Research Findings}

Table 1 provides the profile of respondents.

Table 1. Profile of respondents

\begin{tabular}{lcc}
\hline Gender & & $\%$ \\
\hline Male & 78 & 60 \\
Female & 52 & 40 \\
\hline Age & & \\
\hline Mean & 22.7 & \\
Median & 20 & \\
Mode & 19 & \\
\hline Education & & \\
\hline Graduate & 52 & 40 \\
Post Graduate & 78 & 60 \\
\hline Family Background & & \\
\hline Entrepreneur & 45 & 34.6 \\
Service & 58 & 44.6 \\
Any Other & 27 & 20.8 \\
\hline Total & 130 & \\
\hline
\end{tabular}

\subsection{Ho- Environmental Consciousness and Awareness amongst Millennials Builds Positive Attitude towards Green Entrepreneurship}

The hypothesis proposed that the level of awareness and concern for environment amongst the millennials is high and posed for further growth. The study reveals that in general, millennials possess high level of environmental awareness towards conservation of environment or espousing the cause of environment through preventive action. The respondents displayed concern for the growing degradation of environment through human actions and are convinced about the imminent dangers that such irresponsible actions can accrue. 
The level of understanding environmental issues as well as Eco literacy amongst the respondents showed a considerably positive picture as more than $80 \%$ responded positively to knowledge regarding assessing the damage caused to environment by human actions and increasing pace of industrial pollutants and automation. $83 \%$ of the respondents surveyed displayed a predisposition towards need for preventive actions and undertaking effective communication and action towards prevention of further environmental degradation. Knowledge regarding detrimental effects of environmental pollution on climate change, increasing air pollution and related diseases was found to be considerably high amongst this group and majority of them felt that sensitivity towards the problem can help develop critical thinking and skills to solve the problem in an effective manner.

Figure 2 provides a standard correlation plot between Age, Gender, Beliefs and Eco-Literacy; this is in form of a symmetric square matrix. Each row and column describes a variable e.g Gender, Age and Environmental Knowledge, Belief and Attitude. The size and colour of the dots denote the correlation coefficient, which ranges from -1 to 1 . The diagonal values show the largest dot, which of course denotes 1 . This is since the correlation is represented by the same variables. This correlation is performed by the Kendall methods as given by Kendall ${ }^{\text {p9 }}$. Kendall's tau or Spearman's rho statistic is used to estimate a rank-based measure of association. These are more robust and have been recommended if the data do not necessarily come from a bivariate normal distribution.

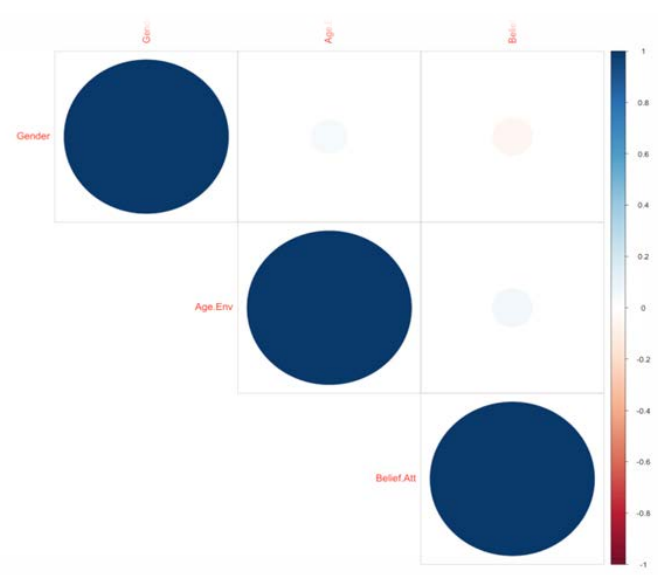

Figure 2. Correlation between age, gender, beliefs and eco-literacy.
A weak Correlation can be inferred between Gender, Age and environmental knowledge, beliefs and attitudes. The coefficients for all pairs lie in the range of $(0,0.015)$ and hence can be treated insignificant.

\subsection{H1 - Motivation for Green Entrepreneurship depend upon Increasing Awareness for Environment- Friendly and Green Products amongst Consumers.}

Undoubtedly, the millennial respondent displayed growing concern for environment, yet it cannot be decisively concluded that awareness and concern have transformed themselves into drivers towards motivating this youth to become entrepreneurs. The shift in attitude and belief is significantly high but motivation towards entrepreneurship varied ranging from 'profitability' to 'innovation,' 'sustainability' and 'ecological commitment' .

In an earlier study by Walley and Taylor ${ }^{31}$, who identified four types of green entrepreneurs- 'Visionary Champions'- who championed the cause of environment and ecologically sustainable business practices. The second type identified was - 'Ethical Mavericks' - who are less driven by green values and commitment but more led by ideas generated through providing plausible solutions to lifestyle or some other problems faced by community. The third category-' Innovative Opportunists' - who sought opportunity in ecological 'niche'. Finally, the last category of green entrepreneurs identified was - 'Ad-hoc 'green entrepreneurs who have adopted green businesses as a matter of chance and whose social and ethical concerns overlapped with motive of profitability in the emerging opportunity.

The present research have also found mixed motives of the young population towards green entrepreneurship.

The following graphical presentations are some of the highlights of the level of environmental consciousness amongst respondents which act as important drivers for green entrepreneurship.

Figure 3 is a bar plot representing distribution of respondents who rated how important Destruction of Ozone is amongst environmental concerns faced by India on a scale of 1-5. The distribution infers that most of the people believe $38.5 \%$ Destruction of Ozone is an extremely serious environmental concern. Only $7.7 \%$ believe that it is not a serious concern at all. 


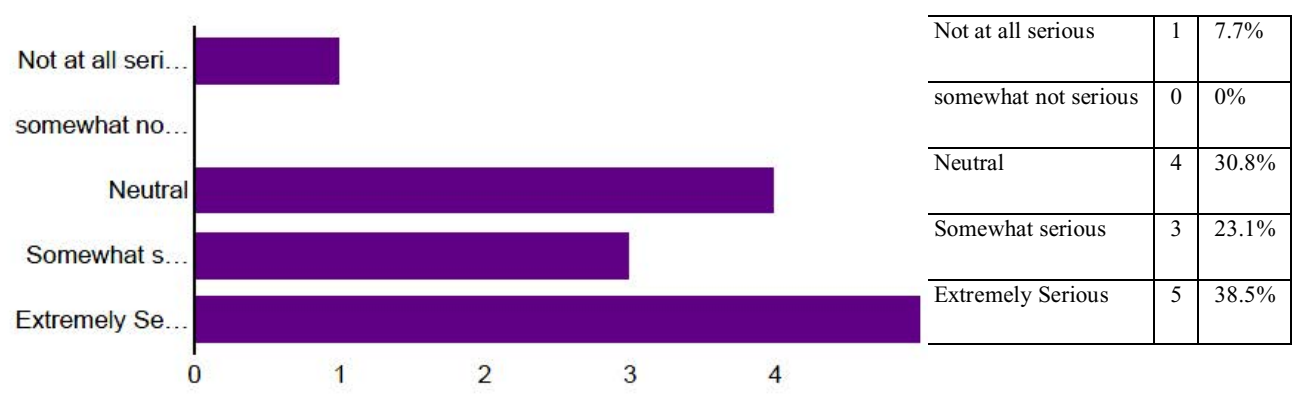

\begin{tabular}{l|c|l|}
\hline Not at all serious & 1 & $0 \%$ \\
\hline somewhat not serious & 0 & $7.7 \%$ \\
\hline Neutral & 4 & $7.7 \%$ \\
\hline Somewhat serious & 3 & $30.8 \%$ \\
\hline Extremely Serious & 5 & $53.8 \%$ \\
\hline
\end{tabular}

Figure 3. Environmental concerns: Destruction of ozone.

Figure 4 is a bar plot representing distribution of respondents who rated how important Global Warming is amongst environmental concerns faced by India on a scale of 1-5. The distribution infers that most of the people believe 53.8 \% Destruction of Ozone is an extremely serious environmental concern. $0 \%$ believe that it is not a serious concern at all.

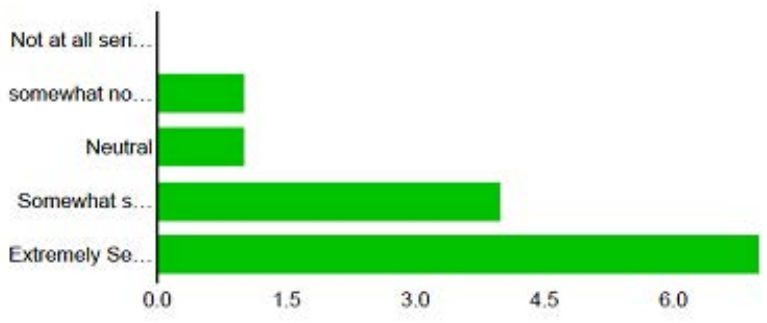

Figure 4. Environmental concerns : Global warming.

Similar plots, as in Figure 3 and 4 were obtained on 9 such topics of environmental concern to audit if the respondents are aware of various environmental concerns. The graphical representation (and others that have not been put in this paper) clearly indicates that the awareness levels and the concern for environment was found to be considerably high amongst the millennial respondents. This is an important factor responsible for development of positive environmental attitudes and beliefs which significantly impacts the demand and supply factor for green products and the success of green marketing eventually.

Figure 5 is a standard factor analysis diagram reflecting various motivational factors that contribute for Green Entrepreneurship. Here are some of the valuable inferences that can be drawn from the factor analysis:

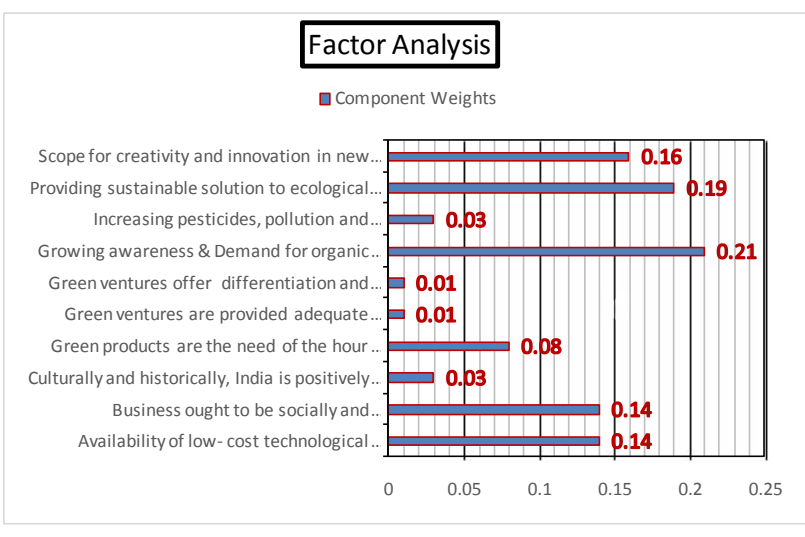

Figure 5. Factor analysis of motivational factors.

- Growing awareness and demand for organic products amongst consumers.

- Providing sustainable solution to ecological perils and prevention of further degradation.

- Scope for creativity and innovation in new emerging opportunities.

- Business ought to be socially and ecologically responsible.

- Availability of low- cost technological solutions to optimize cost in green ventures.

- Green products are the need of the hour and thus a business can be profitable.

- Culturally and historically, India is positively predisposed towards ancient sciences of natural products.

- Increasing pesticides, pollution and contamination in everyday consumable products have shifted consumer preference towards natural ingredients and manufacturing. 
- Green ventures offer differentiation and scope for brand building as a source for competitive advantage.

- Green ventures are provided adequate government support and subsidies.

\section{$6.3 \mathrm{H} 2$-Relevance of Green}

\section{Entrepreneurship is Impacted by Shifts in Potential Demand and Government Policies in Various Sectors in India.}

The relevance of green entrepreneurship is well understood in the millennial group. The overall awareness about environment and the adverse impact of human actions in environment degradation is deeply felt and concern for undertaking actions to improve the scenario has been considerably high. The researched group is aware that that climate change is real and every individual on the planet has to take actions at individual, social and community level to mitigate the crisis.

Faced with the challenge of depletion of natural resources, Energy was considered as the biggest concern for the generation. Most of the respondents felt that energy resources in India, are under severe pressure and expanding industrialization is causing huge demandsupply gap. Awareness about shortfall in electricity generation capacity of the country is well understood by this generation. At the same time, respondents showed high level of awareness regarding renewable alternative energy sources like solar, wind, biogas, natural gas etc. With the abundance of natural energy resources along with favorable factors like large population and geographical location, the scope for growth in clean energy is tremendous and intensive.The respondents, however, felt that the sector can be optimized fully to meet the growing potential through influx of new ideas, innovative thinking, a green supply chain and quick action in terms of clearances and approvals are important drivers to developing the conducive environment to nurture entrepreneurial spirit in his sector.

\section{Policy Scenario}

India's 12th Five-year Plan has clearly laid the road map for environmental concerns and measures and policies have been developed to mark the shift towards a 'lowcarbon' economy. The impetus have been specially placed on encouraging green industries in energy, agriculture, tourism etc.. Stricter norms and regulatory mechanisms have been put in place to discourage highenergy consuming and pollution emitting industries. The focus is on inclusive growth along with low carbon foot print. Small and Medium scale industries have been spearheaded with this important role and 'Cluster approach' is the driving force behind it. This has led to regional innovation hubs which are consistently proving to be strong drivers of green entrepreneurship.

The expansion of solar and other renewable energy sources falls under the aegis of Ministry of New and Renewable Energy. Renewably energy is pursued aggressively and the objective of the government has moved away from policy driven to parity. Entrepreneurs, are equal stakeholders in this development potential. Even at both central and state level, governments have introduced a number of programs like Jawaharlal Nehru National Solar Mission which aims to produce $10 \%$ of its energy from solar - $20 \mathrm{GW}$ - by 2022 . The country has set the goal of capacity addition of 60,000 megawatts in the energy sector by 2017. An investment of over 400 million $\$$ in the sector is bound to enrich the sector with additional capacity and bridge the demand- supply gap. States like Rajasthan and Gujarat have also established frameworks to make solar and other renewable energy affordable for the rural poor. Apart from renewable energy, agriculture and food processing was identified as yet another sector with high potential for green entrepreneurship. Hence, ranging from organic farming, seeds, organic pesticides and fertilizers, solar irrigation pumps, green packaging and a number of others in the realm of food processing, ecolabelling were someof the innovative ideas for green ventures in the agriculture sector.

Moreover, scope for other green businesses like waste recycling, textiles, manufacturing, handicrafts, housing and construction were rated as other important sectors for potential green entrepreneurship. These sectors were credited with as key drivers in creating job opportunities, generating income, economic growthb nad leading the transition towards a green economy. According to Confederation of Indian Industries, Market potential for green products would be worth 300 billion $\$$ by 2025 .

Figure 6 is a standard factor analysis diagram reflecting key drivers that contribute for Green Entrepreneurship. Thus, this factor analysis of various variables various factors in the environment surrounding the emerging green product sector that can prove to be important drivers to strengthen the spirit of green entrepreneurship clearly reflect that the millennials believe that the resources 
required for a green venture are available and supportive policies with respect to protecting environmental are a source of great strength and confidence. The entrepreneurial climate in India is conducive to green entrepreneurship and existing infrastructure and incentives provide the further impetus. Growing concern and demand for green products encourage investment in the sector. Thus, while millennials are highly motivated to embark upon the rising trend, at the same time, the environment surrounding this initiate is also encouraging and proving to be key drivers.

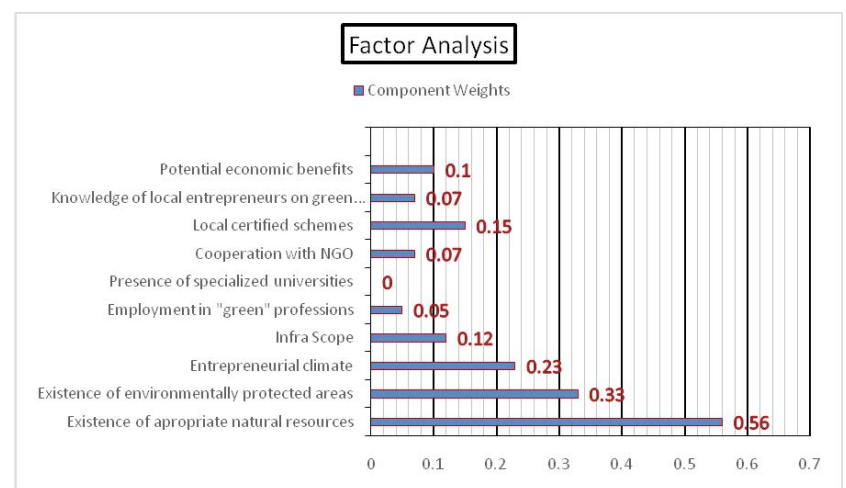

Figure 6. Factor analysis of key drivers of green entrepreneurship.

However, no doubt, the millennials are positive about the emerging growth potential and the various enablers in the environment for green entrepreneurship, yet there are certain shortcomings which, they feel can deter and pose as barriers for the same.

However, no doubt, the millennials are positive about the emerging growth potential and the various enablers in the environment for green entrepreneurship, yet there are certain shortcomings which, they feel can deter and pose as barriers for the same.

Figure 7 is a standard factor analysis diagram reflecting key factors that inhibit popularity of Green Entrepreneurship. According to millennials, is the absence or limited knowledge of green technology and its adaptation to provide solutions to traditional methodology of doing the business. Moreover, high investment costs, absence of funds to undertake risk in the sector are also some of the limitations faced by green entrepreneurs. An emerging potential benefit accrued from green businesses is believed to be hardly understood by investors and hence, a serious discerning factor amongst the respondents.

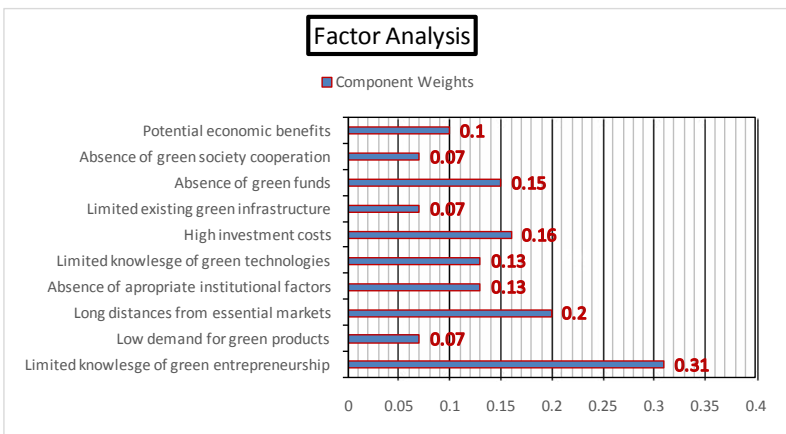

Figure 7. Barriers to green entrepreneurship.

\section{Conclusion}

Thus, the scope for green entrepreneurship is steadily growing and the environment industry is poised to lead from the front in terms of employment and revenue generation. The millenial respondents are aware of the emerging opportunities in th environment industry and are comitted to economic development in the most sustainable manner with environmnetal, social and ethical values inbibed in their green ventures. This positive predisposition has to be aptly supported by adequate ecosystem which incorporates entrepreneurial, training, technology, financial support, tax holiday benefits, concessions etc to leverage the growing motivation of the young population.

A conscious focus to adopt Green economy has to be fostered for the development of green enterprises which would enhance the resilience of economy and a natural bio sysytem. Green entrepreneurship is the most sustainable solution to the rising imbalance of nature and rapid destruction of natural resources. They offer significant contribution, not only in providing employment and genertaing income but also serve as engines of change, harbingers of innovation, new ideas and act as catalyst to adapting new technologies with flexibility and sustainability.The future belongs to the new generation who are inheriting limited natural resources and are thus committed to meet the growing needs of population through efficient and effective utilization of resources while being environmentally and socially responsible.

\section{Recommendation}

Hence, India, of today, is fast transforming into a knowledge based economy and with the high potential and talented 
pool of human resources, it is inevitable to harness this pool to creating a self- sufficient nation of entrepreneurs. It is important, at this juncture, to commit towards building and enabling such environment to develop successful entrepreneurs. Some recommendations can be outlined to make this option a viable one at individual, community and national level. They are as follows :

\section{- Enhancing Green Skills}

Green entrepreneurship cannot be meaningful unless these entrepreneurs understand the true meanng of green businsess. Green skills are the training and knowledge and experience that can be utilized in adapting technology or materials that mimnimze environmental hazard.

\section{- Incubators of Innovation:}

Platform for incubation of innovative ideas before they are set in motion need to be established and an eco sysytem which supports testing of ideas need to created and supported. A strong sysytem would encourage more and more young entrepreneurs to experiment with ideas and test piloting absorbs a great amount of risk.

\section{- Public- Private - Community - Partnership}

A synbiotic relationship is the cornerstone of sustainability of green enterprises. The triad can provide the required mechanism for leveraging innovativion, technological adaption and scalabilty to reach the bottom- of-thepyramid.

\section{- Policy- Designing}

Policy approach to encouraging green ventures need to be put in place and implemented effectively to achieve concrete results of transforming the social and economic landscape of the country. Policy initiatives go a long way in generating confidence and potential to initiate into green ventures,

\section{- Greater Awareness and Attitude Building for Purchasing:}

Need for a positive attitude towards purchasing organic products is imperative to create demand for these products and ensuring a growth for more sectors to adopt geen processes. Hence, awareness drives along with dsplay of better product attributes need to be undertaken through a well designed communication startegy and positive word-of - mouth.

\section{- $\quad$ Start- up Capital :}

A nascent economy and a young entrepreneurial nation, like, India, suffers from a biggest limitation in terms of entrepreneurial intiative and that is lack of financial support and absence of mortgage free loans. This factor deters a lot of young entrepreneurs from undertaking a risk in the unchartered territories. Mechanisms like venture capital, angel investors andsubsidised and easy to procure commercial loans need to be strengthened to bring a larger proportion of population on board.

\section{- Entrepreneurial Education.}

Adequate education in entrepreneurship at school, college and district centres level can provide the right impetus to building not only a conducive environmnet for entrepreneurship for the young minds by creating awareness about environmnet degradation but aslo impart knowledge about various mechanisms to improve the situation. Education can also assist in overcoming social compulsions attached to 'jobs' and 'placement' and start-ups can gain better social acceptance.

Thus, harnessing the potential of potential ecopreneur's is an important factor for generating a transition towards greener economy. Environmnetal problems, today, definitely offer entrepreneurial opportunities and green entrepreneurship is the most sustainable solution to mounting environmental degradtion, climate change,deforestation, rising air, water pollution and depleting biodiversity. Ecopreneurship offers a new paradigmn shift from traditional business maxim of being ' masters' to embracing a matrix of creativity, technological adaptation and product innovation to solve environmnetal problems and thereby act as catalyst in bridging the gap between innovation and market place.

\section{Limitation}

The study has been conducted on a limited sample group of millennials in a particular region. The image of the views held by the respondent group may not necessarily reflect the broader population of the youth. Moreover, the existing study does not affirmatively establish that the environmental beliefs and attitudes would necessarily respond to active environmental activism or entrepreneurship. The study is also limited to a limited geographical area. 


\section{References}

1. Berle G. The Green Entrepreneur: Business Opportunities that can save the Earth and make you money. Blue Ridge Summit, Pennsylvania: Liberty Hall Press : , 1991.

2. Bird BJ. Entrepreneurial Behavior. Scott, Foresman and Company : Glenview, IL ,1989.

3. John CAllen, Stephanie Mallin .Green Entrepreneurship: A Method for Managing Natural Resources? . Journal of International Association for Society and Natural Resources. 2008; 9(21)

4. Issak R. Globalization and green entrepreneurship. Greener Management International.1997; 18;80-91.

5. Sarah E.A Dixon, Anne Clifford. Ecopreneurship : A new approach to managing the triple bottom line. Journal of Organizational Change Management. 2007; 20(3):326-45.

6. Volery. Ecopreneurship: Rationale, current issues and Future Challenges. Conference Papers of Swiss Research Institute of Small Business and Entrepreneurship, St. Gallen, Switzerland, 2002 , pp. 541-553.

7. Gliedt T, Parker P. Green community entrepreneurship: creative destruction in the social economy. International Journal of Social Economics. 2007; 34(8):538-53.

8. Braun. Green Entrepreneurship (GE) and Green Value Added (GVA): A Conceptual Framework. International Journal of Entrepreneurship. 2009;13(S1).

9. Hall JK, Daneke GA, Lenox M. Sustainable development and entrepreneurship: Past contributions and future directions. Journal of Business Venture. 2010;25:439-48.

10. Allen JC, Malin S. Green entrepreneurship: A method for managing natural resources? Society and Natural Resources. $2008 ; 21: 828-44$.

11. Reinhardt FL. Down to Earth: Applying business principles to environmental management. Harvard Business School Press: USA, 2000.

12. Hull CE, Rothenberg S. Firm Performance: The Interactions of Corporate Social Performance with Innovation and Industry Differentiation. Strategic Management Journal. 2008; 29: 781-9.

13. Nill J, Kemp R. Evolutionary approaches for sustainable innovation policies: From niche to paradigm? Science Direct. 2009; 38(4).

14. Hartman CL, Stafford ER. Proceedings of American Marketing Association Summer Educators' Conference., Chicago, IL, USA. 1997.p.56-63.

15. Menguc B, Ozanne LK, Menguc B, Ozanne LK. Challenges of the "green imperative": A natural resource-based approach to the environmental orientation-business performance relationship. Journal of Business Research. 2005; 58(4):430-8.

16. Pastakia CMR, Jensen A. The Rapid Impact Assessment Matrix (RIAM) for EIA.Environmental Impact Assessment Review. 1998; 18:461-82.

17. Lober DJ. Pollution prevention as corporate entrepreneurship. Journal of Organizational Change Management. 1998; 11(1): 26-37.
18. CohenB, Winn MI.Market Imperfections, Opportunity and Sustainable Entrepreneurship. Journal of Business Venturing. 2007;22(1): 29-49.

19. Mahalia von Wallenberg Pachaly. Barriers and Triggers to Green Entrepreneurship: An Exploratory Study. [Master's thesis]. Rotterdam:Erasmus University;. 2012.

20. Keogh PD, Polonsky MJ. Environmental Commitment : A basis for environmental entrepreneurship. Journal of Organizational Change and Management. 1998; 11(1):38-49.

21. Pastakia A. Grassroots ecopreneurs: Change agents for a sustainable society. Journal of Organizational Change and Management. 1998; 11(2):157-73.

22. Linnanen L. An insider's experiences with environmental entrepreneurship. Greener Management International . 2002; 38:71-81.

23. Choi DY, Gray ER. The venture development processes of "sustainable" entrepreneurs. Management Research News. 2008; 31(8):558-69.

24. Kuckertz A, Wagner M. The influence of sustainability orientation on entrepreneurial intentions- Investigating the role of business experience. Journal of Business Venturing. 2010; 25(5):524-39.

25. Schlange LE. What Drives Sustainable Entrepreneurs? Proceedings of 3rd Applied Business and Entrepreneurship Association International (ABEAI) Conference, Kona, Hawaii. 2006 November. 16-20.

26. Isaak R. Green Logic: Ecopreneurship, Theory and Ethics. West Hartford, Kumarian Press. 1999.

27. O'Neill GDJr, Hershauer JC, Golden JS. The Cultural Context of Sustainability Entrepreneurship. Green Management International. 2009; 55:33-46.

28. Sine WD, Lee B. Tilting at Windmills ?The environmental movement and emergence of the US wind energy sector. Administrative Science Quaterly. 2009; 54:123-55.

29. Meek WR, Pacheco DF, York JG. The impact of social norms on environmental action : Evidence from the environmental entrepreneurship context.Journal of Business Venturing. 2010; 25(5):493-505.

30. Linnanen L. An insider's experience with environmental entrepreneurship. Greener Management International. 2002;38:71-81.

31. Walley EE, Taylor DW. Opportunists, champions, mavericks ?.... A Typology of Green Entrepreneurs. Greener Management International. .2002; 38:31.

32. Thornton PH. The Sociology of Entrepreneurship. Annual Review of Sociology. 1999; 25: 19-46.

33. Schwartz SH. A Theory of Cultural Value Orientations: Explication and Applications. Comparative Sociology. 1992; $5(2,3)$.

34. Williamson OE. The New Institutional Economics : Taking Stock, Looking Ahead. Journal of Economic Literature . 2000;38:595- 613 .

35. Hayton JC. National Culture and Entrepreneurship: A review of behavioural research. Entrepreneurship Theory and Practice. 2002; 26(4):33-52.

36. Scott S. A General Theory of Entrepreneurship-The In- 
dividual - Opportunity Nexus. Edward Elgar Publishing, USA, 2003.

37. Granovetter M. Economic Action and Social Structure: The Problem of Embeddedness. American Journal of Sociology. 1985; 91(November):481-510.
38. Prahlad CK. Co-creating Unique Value with Customers. Strategy and Leadership. 2004; 32:4-9.

39. Kendall MG. A New Measure of Rank Correlation. Biometrika. 1938; 30:81-93. 